\author{
Military Technical College \\ Kobry El-Kobbah, \\ Cairo, Egypt.
}

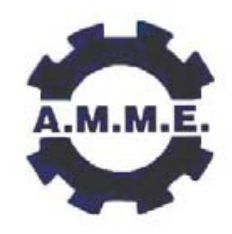

\title{
A SURVEY ON THE STRUCTURAL FAILURE ANALYSIS DUE TO IMPACT
}

\author{
IBRAHIM M.A., YOUNES M.M. and Y.I. EL-SHAER
}

\begin{abstract}
This paper reviews the recent researches in relation to the penetration and/or perforation of metallic and composite target materials. The present survey deals with targets impacted by projectiles travelling at intermediate velocity regime. The deformation domain of various structural targets was mostly localized and existed within a small region of 2-3 the projectile diameter. Recent years have a wide range of significant experimental investigations related to the projectile-target configurations. Although most of the work done have been concerned with the normal impact on monolithic materials by using non-deformable projectiles, valuable examinations were carried out on the inclined impact. Furthermore, impact performed by using deformable projectiles was surveyed on non-homogeneous materials and composites included laminated targets. It was found that through-the-thickness reinforcements enhanced the ballistic resistance of the ceramic armours.
\end{abstract}

The analytical developments enabled to predict the important characteristics of the penetration and/or perforation process were reviewed. These simulations are able to model the local failure modes and the global deformations of various target geometries. In particular cases, when both the local and the global deformation mechanisms were acted in an irregular behaviours during the target collapse, the ordinary models were incapable of predicting accurately the target response and more complicated models were strongly recommended. The common numerical codes mostly used in the simulation of the structures under impact are briefly reviewed and their capabilities and limitations are deeply discussed.

\section{KEY WORDS}

Perforation; failure modes; deformation shapes; collapse mechanisms 


\section{INTRODUCTION}

The field of structural impact covers an extremely wide range of applications and is of interest to engineers of different disciplines. Indeed whenever two bodies collide or risk collision the subject of impact dynamics arises. In the military applications field, scientists need to understand this important subject in order to design armours and to improve the performance of ballistic missiles.

A commonly used measure of a target's ability to withstand projectile impact is its ballistic limit. Much work has been carried out by researchers to estimate this parameter. Generally, the ballistic limit of a target is the greatest projectile velocity the target can withstand without perforation occurring. Precise definitions of this parameter vary depending on the interpretation of the term "perforation" a more detailed discussion concerning these terms can be found in [2]. There are different mechanisms by which a target can fail and these mechanisms may occur singly or in combinations. Reference [2] identified the eight most commonly occurring failure modes of thin or intermediate targets. The large number of penetration and failure mechanisms present, coupled with the added complication of global structural response of the target, makes prediction of events arising from impact loading extremely difficult. In the past, engineers have had to rely exclusively on a few empirical or semi-empirical equations to obtain penetration data. The first formulae were developed in [2] and [6] for the prediction of penetration depths into semi-infinite targets (targets where the distal surface does not affect the penetration process) when struck normally by a projectile.

The advent of battleship armour in the 19th century led to the development of equations predicting the penetration depth of finite thickness armour [7], which have been extensively used by impact engineers. In recent years appreciable advances have been made in the analytical modeling approach to the problem of penetration. these models were gradually become more sophisticated and more accurate. However, these simulations were adapted using experimental data to justify certain assumptions made and to supply various parameters to the models.

In this survey, the importance of the experimental data is reflected on the improving and the understanding of penetration and perforation processes in most recent armours materials. The advanced predicting methods were extremely important in identifying and explaining penetration and perforation phenomena and continue to constitute the main body of research. Numerical methods have been relatively successful in predicting the response of targets to projectile impact. However, a brief discussion of some recent attempts at using such techniques to model the mechanics of penetration and perforation of thin-walled to intermediately thick targets.

\section{BASIC DEFINITIONS}

Perforation: is defined by the entrance of projectile into a target, completing its passage and exit from the other side of target with residual velocity [11].

Penetration: is defined as the continuous travel of a projectile into a target after it has impacted on its surface. It is classified into mushrooming, embedding, and ricochet [11]. 
Ballistic limit: vary in detail, but a simple one is that it is the impact velocity at which the projectile penetrates the target completely but comes to rest in doing so. Another definition to ballistic limit, it is the impact velocity at which perforation just occurs.

There is different definition of the condition at which perforation just occurs. For metal plate these range from the nose of the impactor just breaking through the back face, to the impactor as whole passing through the plate. On this basis if the impact velocity and the ballistic limit are known, the residual velocity of the projectile can be estimated simply. With a sharp-nosed projectile no material is detached from the plate and the residual velocity is

$$
\left.v_{r}=\sqrt{\left(v_{i}^{2}\right.}-v_{b}^{2}\right)
$$

where $v_{r}$ is the residual velocity, $v_{i}$ is the initial velocity, and $v_{b}$ is the ballistic limit.

The ballistic limit often is said to be proportional to the aerial density of the composite (AD) the weight per unit area of composite necessary to provide a given ballistic protection [32].

Impact speed: There are three main ranges of impact speeds [20].

1- At speeds from 1 to15 mls impact behaviour can be related to static or vibration behaviour.

2- At speeds from 150 to $1500 \mathrm{mls}$ dynamic effects make impact behaviour appreciably different from static behaviour, however, material properties can probably be related to their static properties, although strain rate effects are important. This is approximately the range covered by the study of terminal ballistics with bombs, bullets and shells.

3- At speeds from 3000 to $30000 \mathrm{~m} / \mathrm{s}$ behaviour is completely unlike static behaviour in all respects, materials are vaporized and solids flow as liquids, the range includes jets of liquid metal from shaped explosive charges penetrating heavy armour and micrometeorites impacting lightly constructed spacecraft. Fig. (1) shows the impact speed ranges.

\section{TARGETS AND PROJECTILES}

The penetrated body being called the target and the penetrating body the projectile or the bullet. Behaviour depends on the characteristics of both target and projectile as well as on the impact speed.

Targets can be divided roughly into ductile and frangible and the difference between the two is appreciable. Ductile targets are usually of metal and frangible ones are usually of ceramic, soil and concrete. Projectiles can be divided roughly into deforming and undeforming Projectiles. Usually in designing protective layers, it is assumed that the projectile is undeforming, this greatly simplifies the analysis and gives conservative results because when the projectile deforms there is a marked reduction in penetration. Un-deforming projectiles are generally assumed to be either spherical or cylindrical with nose of one of the shapes, flat, conical , ogival and spherical as shown in Fig. (2). 

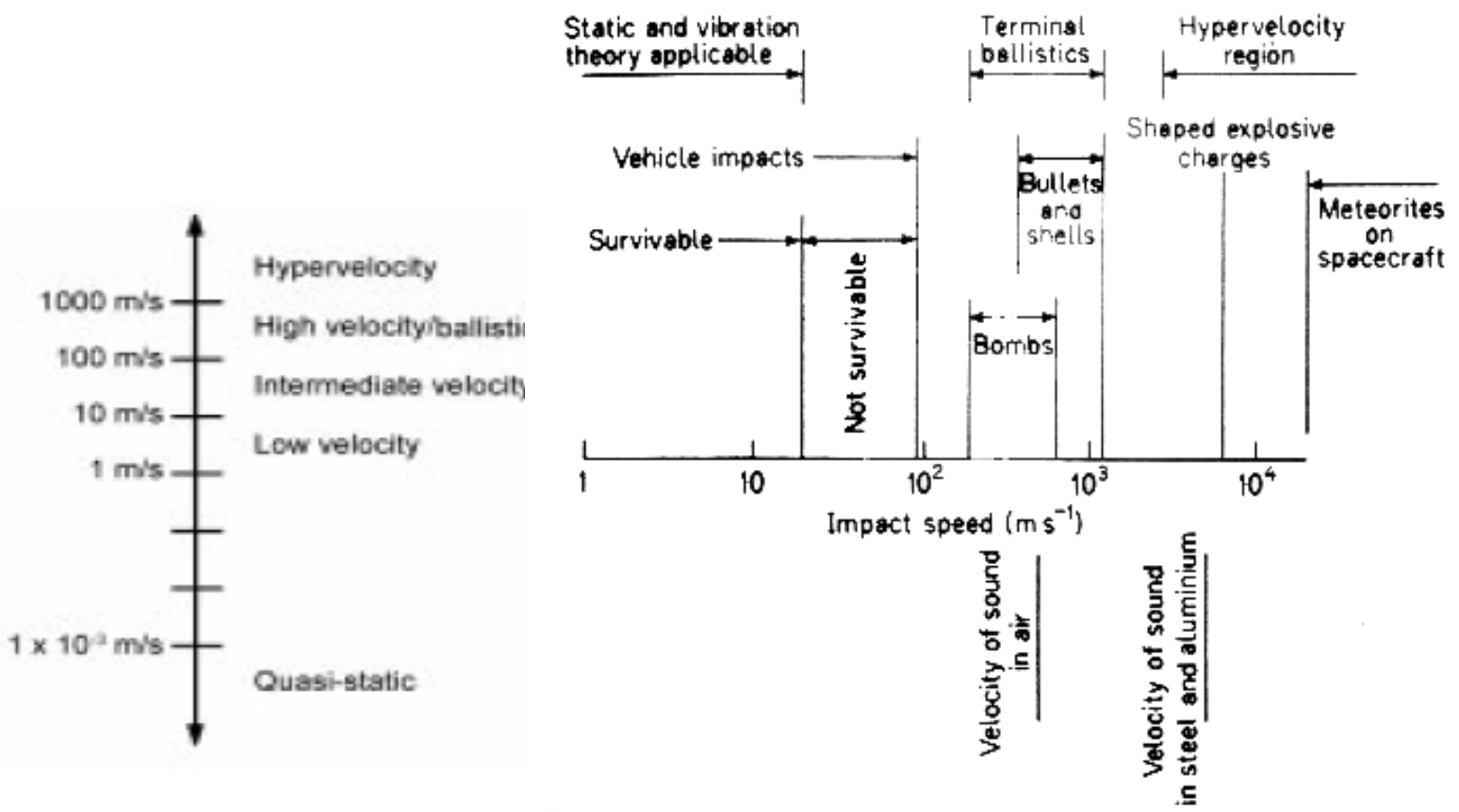

Fig. (1) Impact speeds ranges [1].

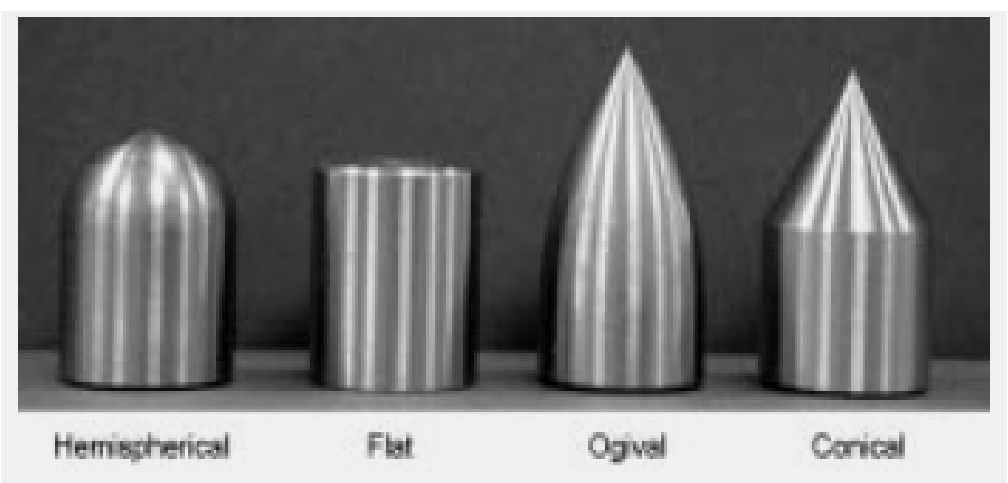

Fig. (2) Typical nose shapes of non-deforming projectiles [2].

As well as the shape of projectile the mass of projectile is important and this is presented in the form of density, because many of the relationships used are empirical, the weight can be used instead of the mass, for instance calibre density is given by:

$$
\rho=W / D^{3}
$$

where $\rho$ is density of the projectile, $W$ is the weight of the projectile, and $D$ is the diameter of projectile.

Based on this definition a long projectile is denser than a short one of the same diameter and material. 


\section{TARGET FAILURE MODES}

Impacted materials may fail in different ways. The actual failure mechanisms will depend on such variables as material properties, impact velocity, projectile shape, method of target support, and relative dimensions of projectile and target. The most common types of failure modes as shown in Fig. (3) are.

- Fracture, as a result of an initial stress wave exceeding a material ultimate strength, can occur in weak and low density targets.

- Radial fracture occurs in such materials where the tensile strength is considerably lower than compressive strength.

- Spalling, tensile material failure as a result of reflection of the initial compressive wave from the rear surface of finite thickness plate, it occurs especially in materials stronger in compression than in tension.

- Scabbing, similar in appearance to spalling, but the fracture is produced by large deformation and its surface is determined by local inhomogeneities and anisotropies.

- Plugging, can be classified into three types: normal plugging failure, adiabatic shear plugging, and fragment failure mode.

- Petaling, is produced by high radial and circumferential tensile stresses after passage of the initial stress wave.

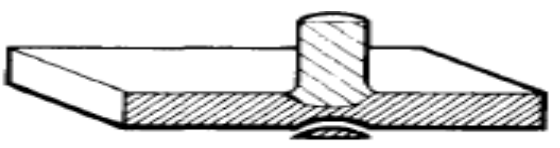

(a) Fracture due to initial stress wave

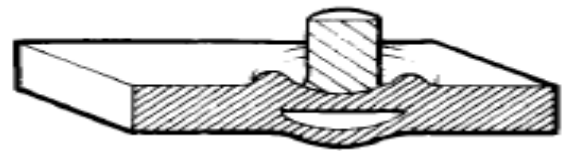

(c) Spall failure [scabbing]

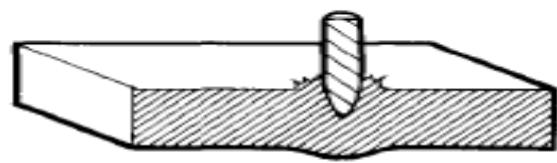

(e) Petaling [frontal]

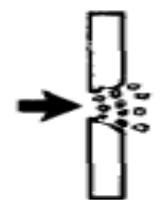

(g) Fragmentation

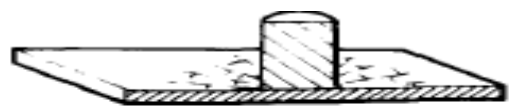

(b) Radial fracture behind initial wave in a brittle target

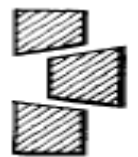

(d) Plugging

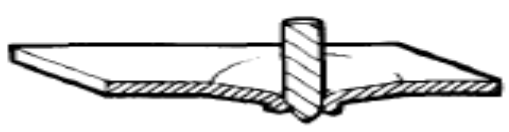

(f) Petaling (rearwards)

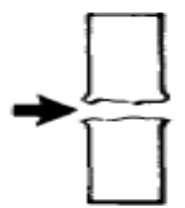

(h) Ductile hote entargement

Fig. (3) typical failure mechanisms [2]. 


\section{PARAMETERS AFFECTING TARGET PENETRATION}

\section{Effect of Target Thickness}

Analysis of the penetration of metal plates is usually restricted to a non deformable projectile striking the plate at right angles to the surface; this gives the simplest analysis and also represents the worst case. The behaviour of the plate depends on its ductility, hardness and the thickness and the size and shape of the projectiles as well as impact speed. Several studies show that at the same conditions, increasing the thickness of the target increases the ballistic limit.

Definitions of plate thickness are very approximate and can vary, as the projectile gets blunter and the plate gets harder the transition from thin plate behaviour to intermediate plate behaviour occurs with thinner plates in broad terms:

- Thin plates are appreciably thinner than the projectile diameter.

- Intermediate plates are approximately this diameter.

- Thick plates are appreciably thicker than this, merging into plates which are infinitely thick $[3,28]$.

\section{Effect of Target Lamination}

This survey reveals that the best configuration is the upper layer from high ductility and low strength material while the lower layer from low ductility and high strength material. This configuration results in nearly $25 \%$ gain in the ballistic limit under moderate detrimental impact $[2,28]$ and helps to clarify the long standing issue of the ballistic resistance of the multi-layered armour configuration.

There may be a transition zone, in which the ballistic limit falls as the plate thickness increases. In this region it would be more effective to use two thin plates rather than one thicker plate. There are other occasions in which a number of thin plates which bend overall as well as perforate absorb appreciably more energy than a single thicker plate which perforates but does not bend overall. The ballistic resistance of metallic monolithic target is found to be greater than that of several adjoining plates of the same thickness; this is considered due to the greater bending resistance of the former. In case of different materials, a double-layered configuration that consists of two parallel layers has a potential improvement over a monolithic plate. On the basis of a series of tests [3] found that multi-layered beams were more effective in resisting perforation than a monolithic beam of the same weight under projectile impact [2] showed experimentally that a double/triple-layered shield was superior in ballistic resistance to a monolithic plate if the total thickness exceeded a critical value. An opposite conclusion was obtained by [3]. They performed normal impact tests on multi-layered shields of a wide range of thickness. The ballistic limit of a monolithic plate was always higher than that of a multiple-layered shield of the same total thickness. This finding was confirmed by [4] through an extensive experimental program on steel plates of varies configurations impacted by standard $7.62 \mathrm{~mm}$ bullet projectiles. $[5,6]$ recently reported a comprehensive experimental and numerical study on the perforation resistance of double-layered steel armour plates. They found that in the case with a blunt-nose projectile, the ballistic limit of a double-layered shield was $30 \%$ higher than that of the monolithic case. These analysis indicates that the protection effectiveness 
of multi-layered shields remains a subject of debate. Note that in those studies various projectiles and target materials were considered. In this connection, two questions can be posed: Under what type of projectile impact would a multi-layered shield be superior in the perforation resistance to a monolithic plate of the same weight? Between ductility and strength, which property is more important for the perforation resistance against projectile impact?

Previous research has revealed that different failure modes may be developed in a target by changing impact conditions [7- 9]. A failure mode with higher energy absorption can significantly improve the ballistic resistance of a shield. By replacing a monolithic plate with a double-layered plate, the bending action can be enhanced and thus the double-layered plate may undergo considerable deformation before fracture. By defining two different grades of metals of various strength and ductility for two layers, the performance of a double-layered shield can be further improved.

\section{Effect of Target Structure}

The structure of the target may be particulate reinforcement, fibbers reinforcement, laminar or hybrid structure. The methods of improving the structure damage resistance of composite target can be divided into five major areas[28] ; matrix toughening, fibre toughening, interface toughening, through-the -thickness reinforcements, and hybridizing [26]. Evaluation of ballistic performance of ceramics has been a difficult task due to the number of variables, like the type of threat, projectile velocity, projectile geometry [12], nature of ceramics, target configuration in terms of front and backing material and their thicknesses, angle of impact and support conditions, affecting the results. However, the depth of penetration (DOP) method [12-16] has been found to be quite satisfactory for the purpose. In this paper, an attempt has been made to study the ballistic efficiency of two grades of alumina ceramics, backed by thick metal plates, against impact of $12.7 \mathrm{~mm}$ armour piercing (AP) projectiles. The thickness of the ceramic tile and the impact velocity of the projectile were varied and influence thereof on the ballistic efficiency studied. Comparative studies with $7.62 \mathrm{~mm}$ AP projectiles were also made keeping the projectile diameter to plate thickness ratios same as those for $12.7 \mathrm{~mm}$ projectiles. The ceramic layer consisted of nine tiles, each of size $50 \mathrm{~mm} \_50 \mathrm{~mm}$, bonded close together over aluminium armour backing plate without any other additional confinement. This configuration was chosen in order to localize the damage, which is a common requirement in modern armour. In the ballistic tests shown schematically in Fig. (4), the alumina ceramic tiles backed by metal plate targets were impacted by the $12.7 \mathrm{~mm}$ AP projectiles and the DOP was measured in each case. Following the approach given in [17], ballistic performance is assessed by a dimensionless factor which combines the mass efficiency and thickness efficiency of the material as defined in the following three equations.

At different velocities, the ballistic performance of ceramic is calculated by comparing the DOP $\left[P_{\mathrm{REF}}\right]$ of the projectile in a semi-infinite thick aluminium alloy (Al-7017) target plate to the residual penetration $\left[\mathrm{P}_{\mathrm{RES}}\right]$ in the plate when backing against ceramic armour tiles of various thicknesses. Ballistic performance of the ceramic is calculated in terms of the thickness efficiency $\left[\mathrm{E}_{\mathrm{t}}\right]$, the mass efficiency $\left[\mathrm{E}_{\mathrm{m}}\right]$ and the ballistic efficiency factor $\mathrm{q}^{2}$ as given below [28].

$$
\begin{aligned}
& E_{t}=\left(P_{\text {REF- }}-P_{\text {RES }}\right) / T t \\
& E_{m}=E_{t}{ }^{*} \rho_{R E F} / \rho_{t}
\end{aligned}
$$




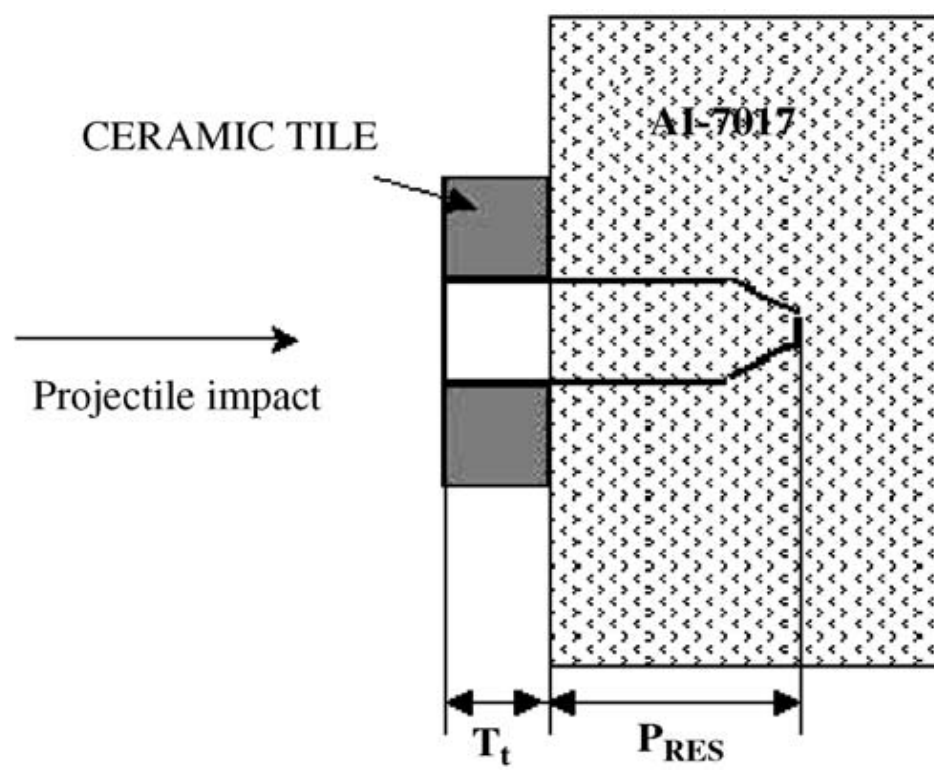

Fig. (4) Target configuration in the DOP test [28].

and

$$
q^{2}=E_{t} * E_{m}
$$

where $q$ is the ballistic efficiency, $E_{m}$ is the mass efficiency, $E_{t}$ is thickness efficiency, $P_{R E F}$ is reference penetration in Al-alloy, $P_{\text {RES }}$ is residual penetration in backing plate, $T_{t}$ is thickness of ceramic tile, $\rho_{R E F} \quad$ is density of backing Al-alloy plate, and $\rho_{t}$ density of ceramic target.

The ballistic efficiency factor has a significance for armour designers as this factor connects both the mass and the thickness efficiency factors. For example, values of 1.0 or above for $E_{t}$ and $E_{m}$ indicate that the ceramic material under evaluation is thinner and lighter than the equivalent reference material (Al-7017 in this case) for the specified threat and are indicative of superior performance. Figure (5) shows an arrangement of ceramic tiles with aluminium backing plate used as armour structure.

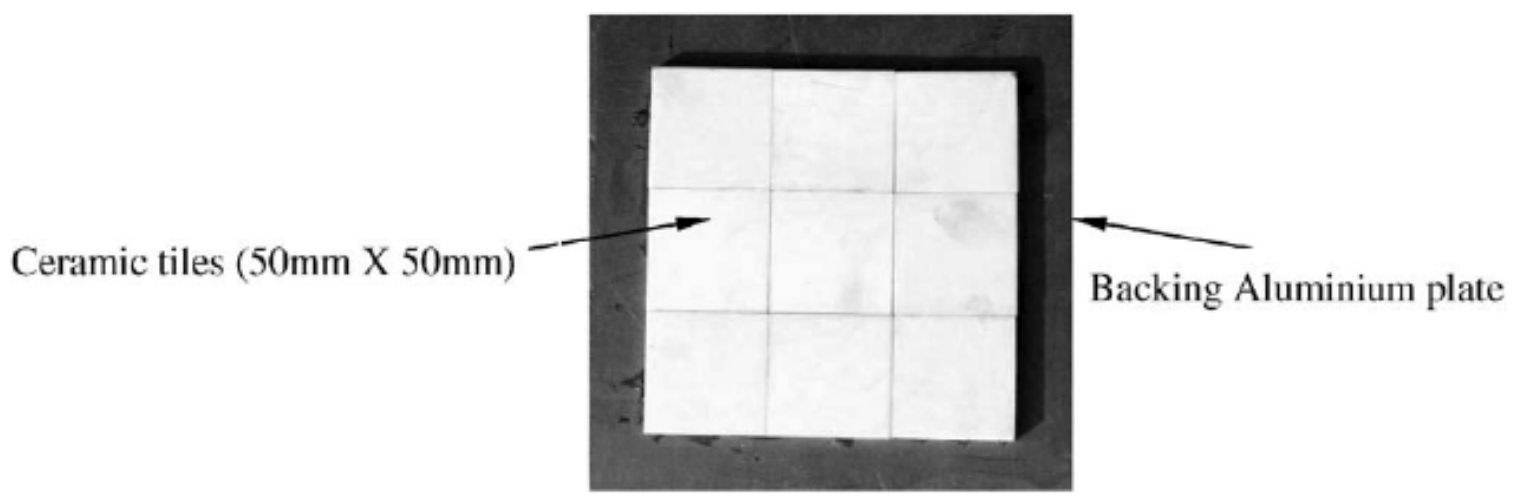

Fig. (5) ceramic tiles bonded to Al-plate [ 28 ] . 
The penetration of projectile obtained in the reference backing plate for each velocity was also measured. In this case, two $40 \mathrm{~mm}$ thick aluminium alloy plates were bonded together and projectiles were fired on the combined target to measure the reference penetration. An average of 3 readings was taken. Using the data of residual penetration and the reference penetration, calculations of the thickness efficiency $\left(E_{t}\right)$, mass efficiency $\left(E_{m}\right)$ and the ballistic efficiency $\left(q^{2}\right)$.

The efficiency increases linearly with the increase in velocity for the range of tests conducted in the present study [28]. The increase in efficiency is found to be greater in $99.5 \%$ ceramic than in the $95 \%$ grade. This dependence may be written in the form:

$$
\begin{aligned}
& q^{2}=0: 002 V-C_{1} \quad \text { for } C 99.5 \\
& q^{2}=0: 0007 V-C_{2} \quad \text { for D95 }
\end{aligned}
$$

where $C_{1}$ and $C_{2}$ are constants for a given thickness. The constants $C_{1}$ and $C_{2}$ are found to be dependent on thickness of the ceramic tile as

$$
\begin{aligned}
& \mathrm{C}_{1}=0: 069 \mathrm{~T}_{\mathrm{t}}-0: 0097, \\
& \mathrm{C}_{2}=0: 024 \mathrm{~T}_{\mathrm{t}}+0: 517 .
\end{aligned}
$$

From the results, it is observed that the mass efficiency increases by a factor of about 1.9 when velocity changes from 500 to $800 \mathrm{~ms}^{-1}$ in case of $99.5 \%$ grade alumina. But the increase in $95 \%$ grade is only by a factor of about 1.6. From Fig. (6) it can be seen that the efficiency of $99.5 \%$ grade is significantly higher than that of the $95 \%$ grade at any given thickness or impact velocity.

This can be partly attributed to the higher hardness and corresponding dynamic strength of $99.5 \%$ grade of alumina ceramic than the $95 \%$ grade and partly to the difference in microstructures of the fractured surfaces. Rosenberg and Yesurun [15], in their experiments on $85 \%$ and $90 \%$ grade alumina ceramic, have studied the ballistic efficiency using the thick backing method when impacted by $12.7 \mathrm{~mm}$ and $14.5 \mathrm{~mm} \mathrm{AP}$ projectiles. The thickness of the alumina ceramic tiles used in their experiments varied from 6 to $10 \mathrm{~mm}$. The configuration used in their experiments consisted of one tile of size 100mm_100mm glued by epoxy resin on a thick aluminium 2024-T351 cylinder. Armour piercing projectiles $(12.7 \mathrm{~mm} \mathrm{AP})$ were fired at velocity of about $920 \mathrm{~m} / \mathrm{s}$ with a $73 \%$ scatter on alumina tiles of $85 \%$ and $90 \%$ grades and their ballistic mass efficiencies were found to be 4.2 and 5.0, respectively, for the two grades of ceramic. Their work indicated that the ballistic efficiency of ceramic increases with its normalized effective compressive strength.

Similarly, [16] studied the efficiency of $8.1 \mathrm{~mm}$ thick alumina $(99.5 \%)$ tiles backed by three types of backing materials fired by four different types of projectiles. In the experiments conducted with hard steel projectiles fired at velocities of $899 \mathrm{~ms}^{-1}$ from a $12.7 \mathrm{~mm}$ gun barrel on $99.5 \%$ grade alumina tile of size $75 \mathrm{~mm} \times 75 \mathrm{~mm}$ and of thickness $8.1 \mathrm{~mm}$ that was bonded on an aluminium $5083-\mathrm{H} 115$ alloy plate and confined laterally by a steel surround, a ballistic efficiency of 4.8 was obtained.

The results of our experiments on 10,12 and $14 \mathrm{~mm}$ thick $99.5 \%$ alumina tiles impacted at velocities of about $830 \mathrm{~ms}^{-1}$, when extrapolated to $8.1 \mathrm{~mm}$ thickness, gives an efficiency of 4.6. This is in reasonable agreement with the result in [16] considering the 

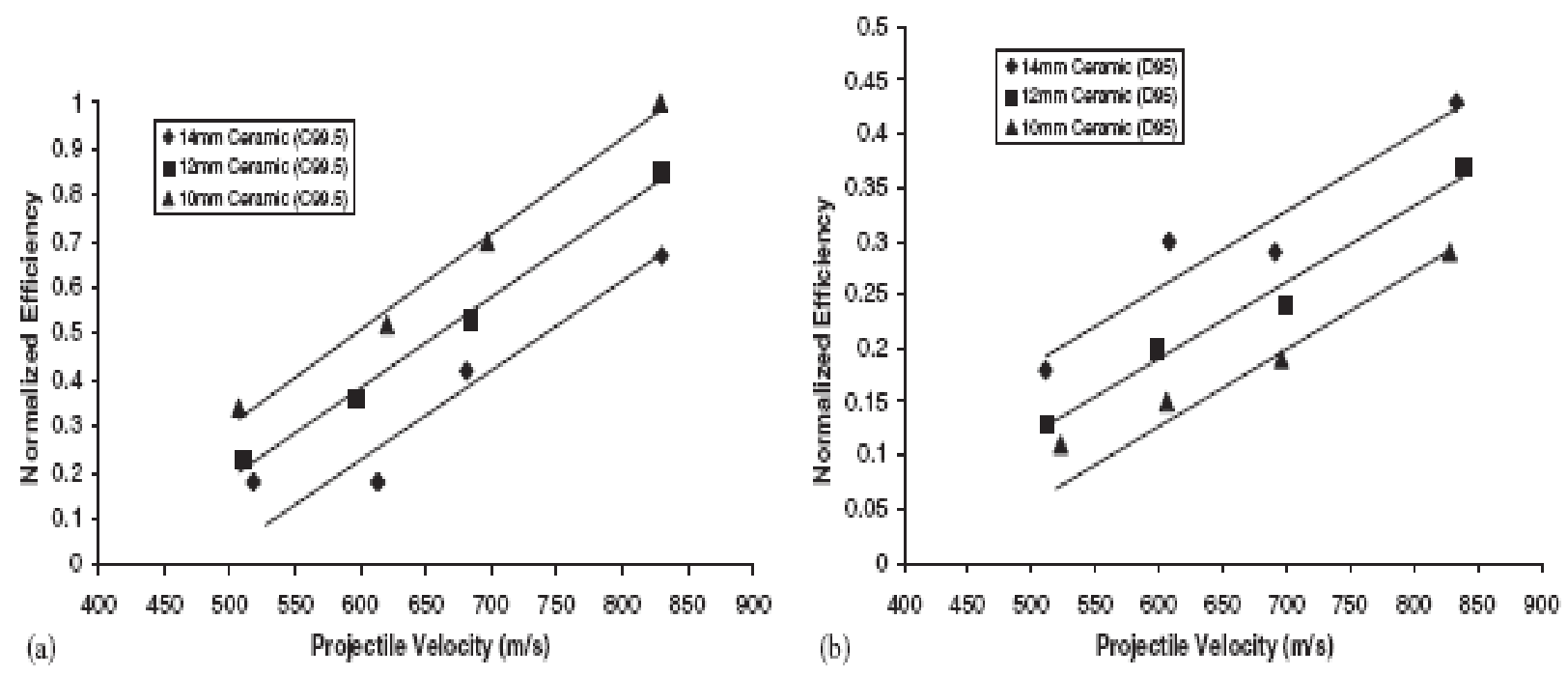

Fig. (6) Normalized ballistic efficiency vs. projectile velocity for ceramic tiles of (a) C99.5 ceramics and (b) D95 ceramics [28].

differences in the velocity of the projectiles, strengths of the backing plates as well as sizes of the tiles used in the two studies.

Reference [18] carried out an experimental study of the ballistic performance of $96 \%$ and $99.8 \%$ alumina ceramic of size $50 \mathrm{~mm} 50 \mathrm{~mm}$ in three different thicknesses ranging from 4.1 to $8.3 \mathrm{~mm}$, when impacted by 0.30 calibre AP projectiles at velocities varying from 576 to $803 \mathrm{~ms}^{-1}$. In their experiments, the tiles were bonded to $6061-\mathrm{T0}$ aluminium alloy plates using adhesive. Their study revealed that the ballistic mass efficiency of ceramic increased with the projectile velocity by a factor of about 1.4 in the case of $99.8 \%$ grade and by about 1.5 in the case of $96 \%$ grade. The ballistic efficiency however decreased with increase in tile thickness by a factor of about 1.3 in both the grades of ceramic. In the present experiments using 12.7 AP projectiles, it is seen that the mass efficiency increased with increase in velocity by a factor of about 1.9 in the case of $99.5 \%$ grade and by about 1.6 times in the $95 \%$ grade of ceramic. This trend is like the ones observed by [18] against 0.30 AP projectiles. With the increase in the thickness of ceramic tile. it is seen that the mass efficiency decreased by a factor of about 1.3 in the case of $99.5 \%$ grade but increased by a factor of 1.3 in the case of $95 \%$ grade.

In order to compare the effect of ballistic efficiency of ceramic against the two different projectiles, a study was carried out using 7.62 AP projectiles, which is also close to $0.30 \mathrm{AP}$ projectiles. Experiments were conducted in such a way that the ratio of the diameter of projectile to tile thickness, $(\mathrm{d}=\mathrm{t})$, are similar. For this purpose, 7.62 AP projectiles having a diameter of $6.2 \mathrm{~mm}$ were fired at velocity of $829 \mathrm{~ms} 11$ on a $8 \mathrm{~mm}$ thick $99.5 \%$ grade ceramic tile. The data is presented in Table 4 . The $\mathrm{d}=\mathrm{t}$ ratio is 0.8 , wherein the mass efficiency is obtained as 3.8. Comparison can be made with the results on $12.7 \mathrm{~mm}$ AP fired at velocity of $830 \mathrm{~m} / \mathrm{s}$ on $14 \mathrm{~mm}$ tile of same grade giving a $\mathrm{d}=\mathrm{t}$ ratio of 0.8 . The mass efficiency obtained was 3.5. The difference in efficiencies for same $d=t$ ratio is about $8 \%$. Another comparison was made using $6 \mathrm{~mm}$ thick tiles fired against 7.62 AP with a $d=t$ ratio of 1.03 that gave a mass efficiency of 5.0. This, when compared with the result of $10 \mathrm{~mm}$ thick tiles of same grade when fired against 12.7 AP 
giving a $d=t$ ratio of 1.08 , gave an efficiency of 4.2 . The difference in efficiencies is about $20 \%$. From this data it is seen that $d=t$ could be a good parameter to be kept identical for a rough comparison of the ballistic efficiency of ceramic tiles when used against projectiles of different diameters provided the method of evaluation is same. However, more such experiments need to be performed to confirm the use of such an approach. Figure (7) shows the variation of the normalized ballistic efficiency against the tile thickness for different velocities of the projectile. From the data, it is observed that with the increase in thickness of the ceramic tile, the ballistic efficiency factor for a given velocity decreases by a factor of about 1.3 in the case of $99.5 \%$ grade for all the velocities, whereas it increases by nearly the same amount in the case of $95 \%$ grade ceramic.

This 'thickness effect' is actually a result of two distinct effects: (a) the free surface effect and (b) the velocity effect. The free surface at the top of the ceramic generates release waves, which cause cracking and reduced stresses, thereby decreasing the resistance. The effect of this on the overall performance diminishes with the increase of thickness of the ceramic giving rise to an apparent increase in the overall performance. The "velocity effect" is a consequence of the decreased performance with decrease in velocity. For any given incident velocity, there is a definite and strong gradient of velocity as the projectile moves from the top of the ceramic to the bottom.

Essentially then, a thick ceramic tile can be considered to be made of elemental thicknesses, wherein each succeeding layer encounters the projectile at a lower velocity than at the previous layer and hence exhibits a corresponding lower efficiency. The average efficiency, being an average over the whole thickness, therefore decreases. The net effect due to the "free surface effect" and the "velocity effect" depends on which one between the two effects is dominant for any given ceramic. In the case of $99.5 \%$ grade, the velocity effect which is higher, apparently dominates and leads to a decrease in efficiency with an increase in tile thickness. In the case of $95 \%$ grade for which the velocity effect is only about $1 / 3$ rd as strong, the surface effect dominates, to create a mild increase in efficiency with increasing thickness.
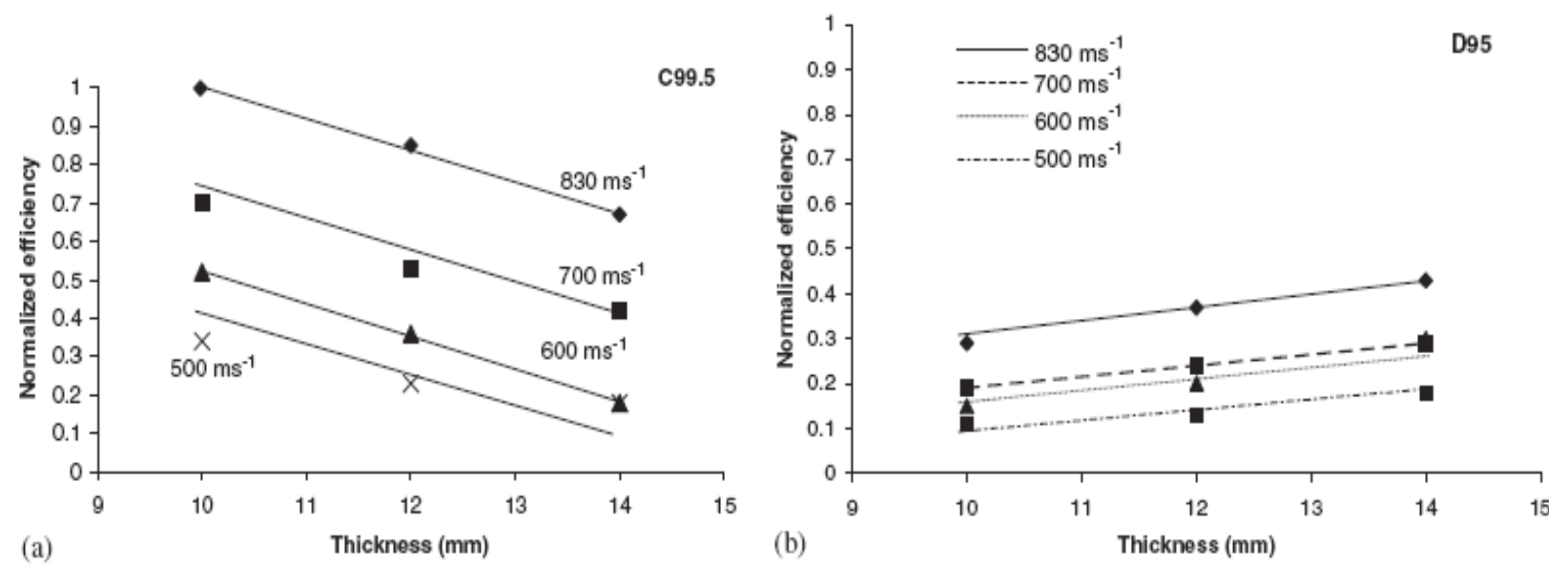

Fig. (7) Normalized ballistic efficiency vs. thickness of ceramic tiles for (a) C99.5 ceramics, (b) D95 ceramics [28].

The above discussion showed that when the Ballistic tests were conducted on high purity alumina ceramic tiles backed by thick plates of Al-7017 aluminium alloy using the 
DOP method. Response of projectiles and the targets were studied, and the ballistic efficiency of the targets were determined. It was found that the efficiency factor is not constant but varies as a function of both thickness and velocity.

The results indicated that the higher purity alumina (99.5\%) shows higher ballistic performance in comparison with $95 \%$ alumina for any given thickness and velocity. In the case of high purity alumina, with increase in the thickness the ballistic efficiency factor decreases, while it increases for the lower purity alumina employed in the present tests.

The Optimum design of two-component composite armours against high-speed impact was discussed by $[3,30]$ where a new method for optimizing the design of twocomponent armours is proposed.

The new method formulates the armour design as a generic optimization problem to solve. The objective function is constituted based on the selected design criterion with the use of Florence's model. The optimum design is obtained by using a hybrid evolutionary solving technique. Compared with the analytical design models derived from different design criteria and constraints, the present method provides a generic platform for armour design whereby:

(1) any reasonable design criterion can be adopted to obtain the corresponding design. One may choose the maximum ballistic limit velocity or the minimum areal density or others as the optimization objective, without introducing extra computational complications.

(2) various kinds of design constraints can be easily introduced into the design optimization procedure.

(3) any complicated impact analysis model, in addition to Florence _ model, can be easily introduced.

(4) in addition to the thickness ratio of the front and backing plates, the combination of the armour materials can also be accounted for in the optimization.

\section{Florence's model and analytical design criteria}

Considering a normal impact by a rigid projectile on a two-component armour consisting of a ceramic front plate and a ductile back plate, the modified Florence_s model can be described as follows [2,3,5]:

$$
\begin{aligned}
& V_{\mathrm{p}}=\sqrt{\frac{\alpha \varepsilon_{2} \sigma_{2} h_{2}}{0.91 m_{\mathrm{p}} f(a)}} \\
& f(a)=\frac{m_{\mathrm{p}}}{\left[m_{\mathrm{p}}+\left(\rho_{1} h_{1}+\rho_{2} h_{2}\right) \pi a^{2}\right] \pi a^{2}} \\
& a=a_{\mathrm{p}}+2 h_{1}
\end{aligned}
$$

where $V_{p}$ is the predicted ballistic velocity, $a$ is the coefficient determined from available experimental data, e2 and $\mathrm{r} 2$ are the breaking strain and the ultimate tensile strength (UTS) of the backing plate, q2 and h2 are the density and thickness of the backing plate thickness, $\mathrm{q} 1$ and $\mathrm{h} 1$ are the density and thickness of the front plate, $\mathrm{mp}$ and ap 
are the mass and radius of the projectile, respectively Fig. (8). When $a=1$, the above equations describe the Florence's model [2].

The complete development of Florence's model was presented in Ref. [2]. In this model, the projectile is idealized. as a short cylindrical rod impacting normally into the ceramic, and causing the ceramic to break progressively into a cone of fractured material. This spreads the impact load and accordingly distributes the impact energy to the backing plate over an area larger than the diameter of projectile. The backing plate subsequently deforms as a uniform membrane. Florence's model was derived with several simplifying assumptions and the consideration that the kinetic energy of the rod is equal to the energy absorbed in the backing plate before rupture. Despite the fairly simple expression, the model demonstrated satisfactory agreement with experimental results

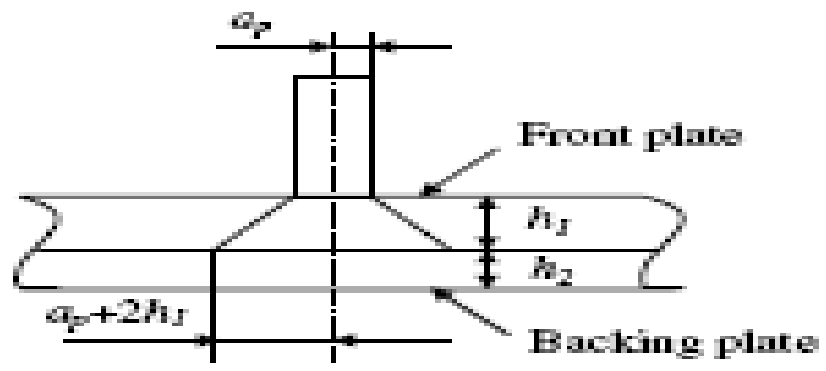

Fig. (8) Florence's impact model [3].

\section{FAILURE CRITERIA OF COMPOSITE MATERIAL}

Berthelot defined the failure criteria as the end of elastic domain that is associated with the development of micro-cracking; it allowed the designer to evaluate the mechanical strength of the composite laminates. Failure criteria may be classified as[13]:

\section{a) Maximum stress criterion}

This criterion predicts the failure of a layer when at least one of the stresses in the material coordinates exceeds the corresponding measured value of the strength.

\section{b) Maximum strain criterion}

This criterion is most popular in industry today; it reads the strain to failure. If the material is linear elastic up to failure then the strain to failure is directly related to ultimate strength value.

\section{c) Energy criterion}

In some applications, the maximum stress theory does not represent adequately the experimental variations of strength. Moreover, there is no interaction between the modes of fracture: longitudinal, transversal or shear fracture. Thus, a strain energy criterion is extended to orthotropic materials and it is defined as the strain energy stored per unit volume of the strained material. 


\section{FAILURE MECHANISM OF CERAMIC COMPOSITE ARMOUR}

All of the ceramic armour systems have one feature in common. Each is a twocomponent system consisting of a facing of hard brittle material and a backing of soft, deformable material. When an armour system is struck by an armor-piercing projectile, the core or penetrator is broken upon impact with the facing, in the first few microseconds. The residual energy is then absorbed by the backing material. The role of the backing has been likened to that of a "catcher's mitt" in this situation. Composite armour systems take advantage of the high strength of the ceramic hard facing, and the ductility and stiffness of the backing material. These two materials are bonded together into a laminate structure[33]. Optimization of the two-component armour system is critical because of the various interactions of the component properties, as well as the nature of the interface between them. On impact, the ceramic is exposed to the projectile core. A major portion of the kinetic energy is absorbed by the ceramic, with residual energy being absorbed by the backing.

The impact of the projectile with the ceramic armour face creates compressive shock waves that transverse forward through the ceramic and backward through the projectile at extremely high pressures of up to $4 \times 106 \mathrm{psi}$ at $3000 \mathrm{fps}(28,000 \mathrm{MPa}$ at $900 \mathrm{~m} / \mathrm{s})$. The shock waves travel through the projectile and the ceramic at the respective sonic velocities of the materials $-16,000 \mathrm{fps}$ for steel and $48,000 \mathrm{fps}$ for B4C $(4,800 \mathrm{~m} / \mathrm{s}$ and $14,400 \mathrm{~m} / \mathrm{s}$ respectively), and the greater the difference in the sonic velocities, the stronger the resulting shock wave will be in the projectile. This results in greater fracture of the projectile core. When the moving compression waves reach free surfaces in both the projectile and the ceramic, the waves are reflected, producing a free surface velocity wave in the direction of the shockwave, and an expansion or rarefaction wave normal to the free surface. The high tension forces at the rarefaction wave front overstress both the projectile and the ceramic, causing both to tear apart. The failure in the ceramic occurs as a conoid radiating away from the impact point. This fracture conoid transfers loading to the backup plate over its larger diameter at the interface, which effectively spreads the high impact loading over a much larger area than the projectile diameter. As the fractured projectile fragments travel into the fractured ceramic, the resulting loading area on the backup plate decreases back down to the projectile diameter.

The backup plate must have the ability to absorb the resultant projectile and fractured ceramic fragment energies by dynamic deflection and thereby decelerate the particles. If the match is correct, all of the projectile residual energy is widely distributed. This prevents localized projectile loading, which could exceed the shear strength of the backing material, resulting in punch out and defeat of the armour system. A possible mechanism of projectile impact on the ceramic composite armour is described in the following sequence of steps:

\section{From $\mathbf{0 - 1 0} \boldsymbol{\mu s e c}$}

The projectile tip is destroyed and backup plate starts to yield at the conoid interface;

\section{From $9-15 \mu \mathrm{sec}$}

The projectile is eroded by the ceramic fragments. About $40 \%$ of impact energy is carried off by eroded projectile material;

\section{After $15 \mu . s e c$}


The backup plate acts to absorb the resulting $60 \%$ energy contained in the fractured projectile and ceramic. The backup plate absorbs the energy by dynamic deflection.

The stopping power becomes greater as the thickness (and therefore areal weight) of the ceramic and backup layers becomes greater. As a general guide, a 3/8" thick layer of densified fibreglass will stop a 0.30 calibre AP (armour-piercing) projectile fired at point blank range (about 6 meters) at 900 meter per second.

During an impact event of a composite material (fibre grid and a resin), the target response is a combination of global and local reactions $[8,33]$. The relative contributions from these two reactions are generally determined by a multitude of factors including, but not limited to, strike velocity, projectile properties, target size and boundary conditions.

Typically, strike velocity is considered to be the most significant factor to determine the transition between locally dominated and globally dominated response as outlined in $[2,6,8,18,33]$. Strictly speaking, the projectile velocity itself does not provide a clear demarcation between the two types of response and other factors, e.g., the ratio of impactor to target mass or the ratio of the local contact frequency to the structural frequency of the target are more robust indicators of the nature of the impact response. However, for a given impactor and target system one may loosely use velocity as a parameter to distinguish between the local and global response.

It is important to recognise that local behaviour is typically independent of target dimensions, whereas global response is inextricably linked to it. This observation is valid even during impact on single yarns Fig. (9). Studying the failure of highperformance yarns subjected to the impact of projectiles flying at different speeds, [6] observed that while the failure mechanism at lower velocities is of a global mode (referred to as 'transmitted stress wave'), it changes into local ('shear or plug' failure) at higher strike velocities. The range of strike velocities from global to local dominated response covers quasi-static loading at the low end and hyper-velocity impacts at the high end, (Ursenbach 1995).

At high enough velocities, global plate deflection becomes much less important Fig.(10). In cases where damage is experienced, modes can vary greatly and include indentation, matrix cracking, delamination, fibre shearing (cutting and/or punching), and fibre tensile failure $[2,6,8,18,33]$.

The degree to which each of these regimes is observed is a function of strike velocity, target and projectile geometry, and material properties.

The global energy absorbing mechanisms are usually dominant in low-velocity impact events, where there is ample time for the projectile energy to be transferred and spread through a large area of the target. In such cases, the impact event is long enough for the elastic waves (flexural and shear) generated in the target to propagate and reach the boundaries of the target. The impact response of single yarns, as the basic component of fabrics and laminates, has fundamental similarities to that of fabricbased targets. It is now generally accepted that a longitudinal strain wave, travelling at the speed of sound in the material, is generated in a fabric yarn upon impact. This wave stretches the yarns and causes the material to move in-plane towards the impact point. 
(a)
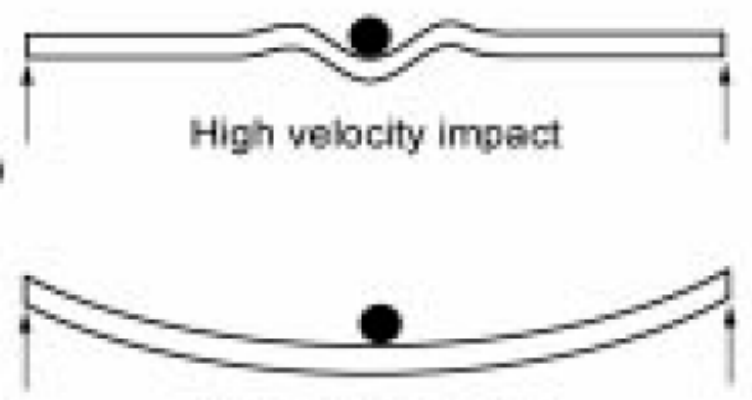

(b)

Low velocity impact

Fig. (9) Schematic representation of the impact response under (a) high velocity impact loading (b) low velocity impact loading [10].
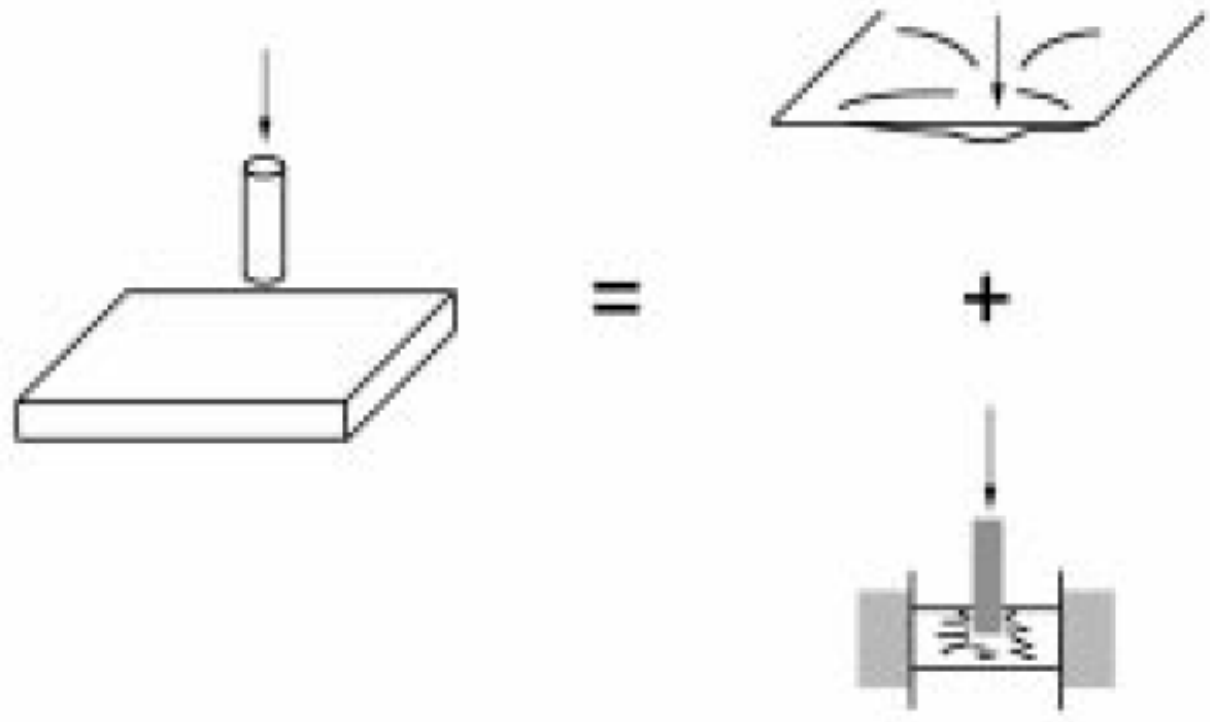

Fig. (10) Concept of superposition for global/local response [10].

A deformation cone is also created, with a wave front that travels at a much lower speed than the longitudinal wave. The in-plane motion of the material changes into outof-plane at the rim of the deformation cone. The tent-like shape of this cone is due to the transverse deflection of the warp and weft yarns in the orthogonal directions. These two waves expand with time, increasing the energy stored in the fabric until the projectile is stopped, or the target is perforated by the projectile $[8,12]$. Strike velocities less than $100 \mathrm{~m} / \mathrm{s}$ will usually elicit predominantly global response from the target, this is characterized by a high degree of elastic behaviour by the system.

Global deflection occurs as flexural waves travel to the boundaries and back many times within the time-frame of the impact event. Generally speaking, increasing the number of reflections over the duration of the event has the effect of making the event approach a quasi-static response. 
Examples of quasi-static impact are tools dropped on a structural component during maintenance or runway debris strikes during take-off and landing of an aircraft. In these cases penetration or perforation is rarely experienced. However, damage can still be present and quite often will be below the surface and more accurate definitions of quasi-static versus dynamic response.

There are three types of models that can be used to describe impact dynamics Fig. (11), these are:

1. Energy-balance models which assume quasi-static panel behaviour and are therefore the simplest approach available.

2. Spring-mass models, such as the ones shown in Fig. (12), which accounts for the dynamics of the structure in a highly simplified manner.

3. Complete models where the dynamics of the structure are fully modelled.

The models are increasingly more representative of the event, with a corresponding increase in computational expense. Ideally, a range of models would be used in any given study \pm simple ones to gain insight, and complex ones to capture subtleties and study various parametric effects.

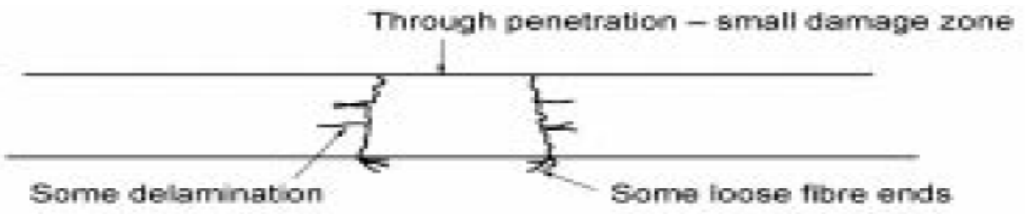

(a) High welocity impact damage

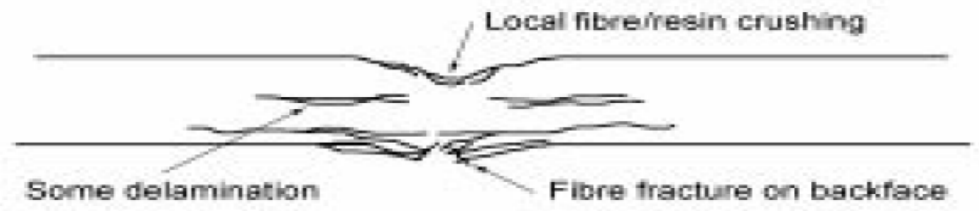

(b) Intermediate welocity impact damage

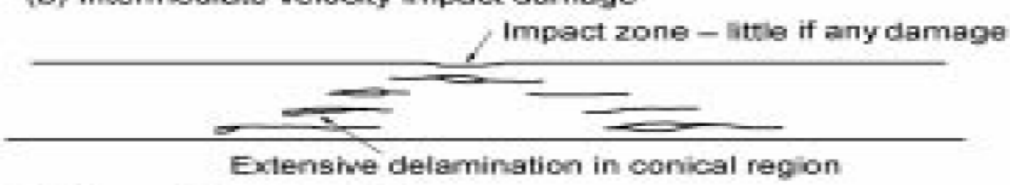

(c) Low velocity impact damage

Fig. (11) modes in laminated composites resulting from various impact velocities[10].

Strain energy stored in the fabric, such as boundary conditions, will be discussed in later sections. The kinetic energy transferred to a fabric target is composed of in-plane motion of the material outside the deformation cone in the wake of the strain wave front, and the out-of-plane motion of the yarns in the deformation cone. The kinetic energy of a fabric system is affected by the mass (or areal density) of the target, and the volume of the material in motion. As with the strain energy, the kinetic energy can also be affected by the boundary conditions imposed on the target. For hard composites, the mechanisms are basically the same as would be predicted via classical elastic behaviour. By definition, the elastic energy is temporarily stored in the system and returned. In the case of an impact that induces no damage, it is the only 


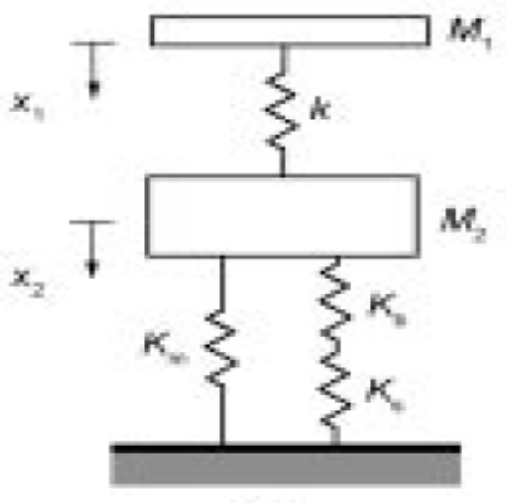

(a)

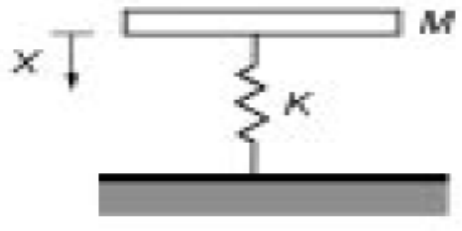

(b)

Fig. (12) (a) Two degrees of freedom (a) spring-mass model. (b) Single-degree-of-freedom model (Abrate 2001).

mechanism other than system losses. A variety of models exist which attempt to address the global component of deformation and energy is a means by which the global stiffness of the structure is calculated and used for predicting the elastic energy absorption as well as the global component of deflection and potential modes of vibration.

Taking into account the effects of shear deformation and rotary inertia. Projectile impact is taken as a time-varying normal force applied to the centre of the panel, and the exact response of the panel in terms of penetration resistance is determined by the amount of local damage or penetration handled separately from the global aspects. Typically, however, a finite-element method is employed to determine the elastic energy absorption. The local response refers to the behaviour of the target within close proximity to the projectile contact point.

As strike velocities increase, a target panel will exhibit increasing amounts of locally dominated response. However, this does not imply that the behaviour at high velocities is necessarily different. For instance graphite epoxy the dynamic failure modes are very similar to quasi-static ones. The mechanisms discussed here often occur in stages throughout the penetration event and can be very dependent upon indenter tipgeometry Figs. $(13,14)$.

Discussion of what influences these mechanisms will be covered in a later section. The various mechanisms are now introduced in approximately the order in which they would occur during a penetration event.

In high velocity impact of both hard and fabric composites, the projectile usually perforates the first few layers of the target upon impact. This phenomenon, referred to as shear plugging, occurs more often with projectiles that have sharp edges, or when the initial strain in the yarns exceeds their failure threshold. The subsequent layers in the fabric or hard target are stretched and absorb the energy placing the high performance layers on the distal side of the target. With blunt indenters, plugging is the final damage mechanism which occurs. 


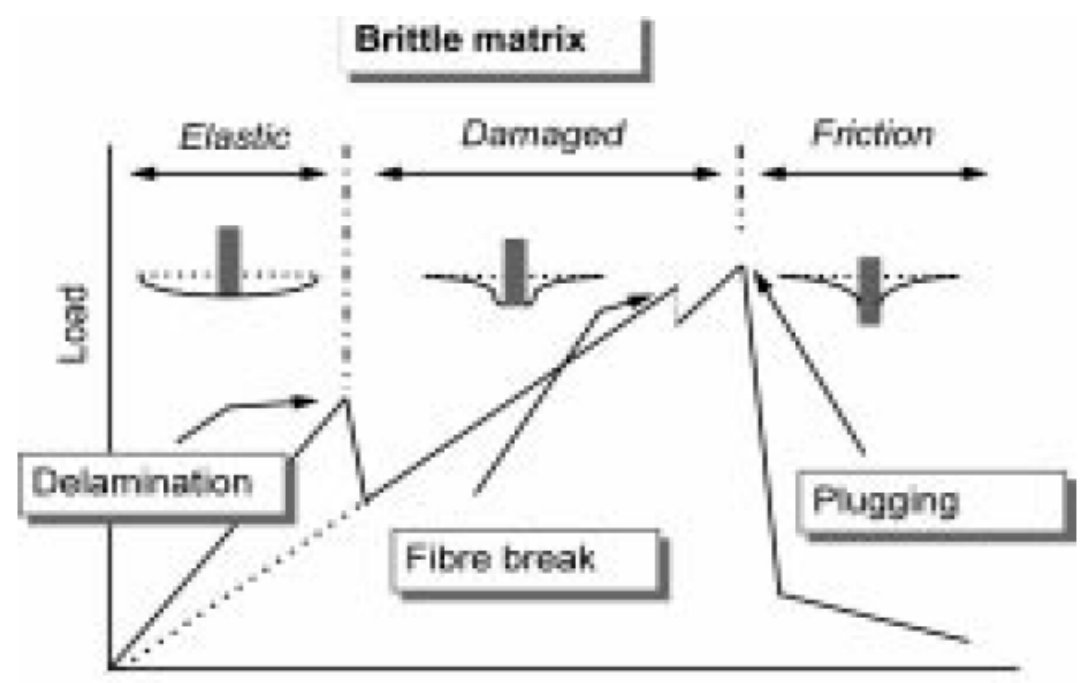

Punch displacement

Fig. (13) Idealized load-displacement curve for brittle matrix

CFRP static penetration test [8]

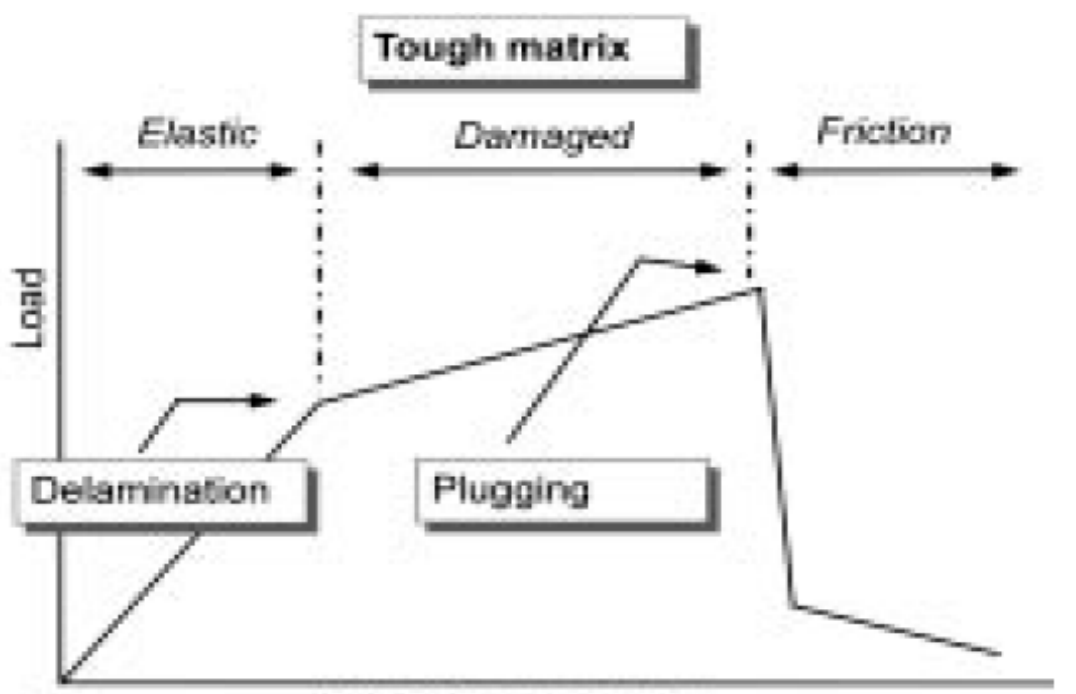

Punch displacament

Fig. (14) Idealized load-displacement curve for tough matrix CFRP static penetration test [8]

Typically the plug is a circular section of material cut out in front of the indenter when perforating stiff plates. This mechanism has been illustrated in Fig. (15).

$[2,10,33]$ have determined that the most important energy loss mechanism for a projectile impacting a ceramic composite target occurs due to the loss of projectile mass (Step 2 described above). It has been estimated that an extension of the time duration of this step by only 2 milliseconds could increase the ballistic limit by about $10 \%$. Since the time of break up of the ceramic is directly related to the duration of the projectile erosion phase, it is seen that to improve the composite armour system, the integrity of the ceramic must be maintained for as long as possible Wilkins et al $[2,33]$ have suggested two distinct ways to accomplish this task see Fig. (16). 

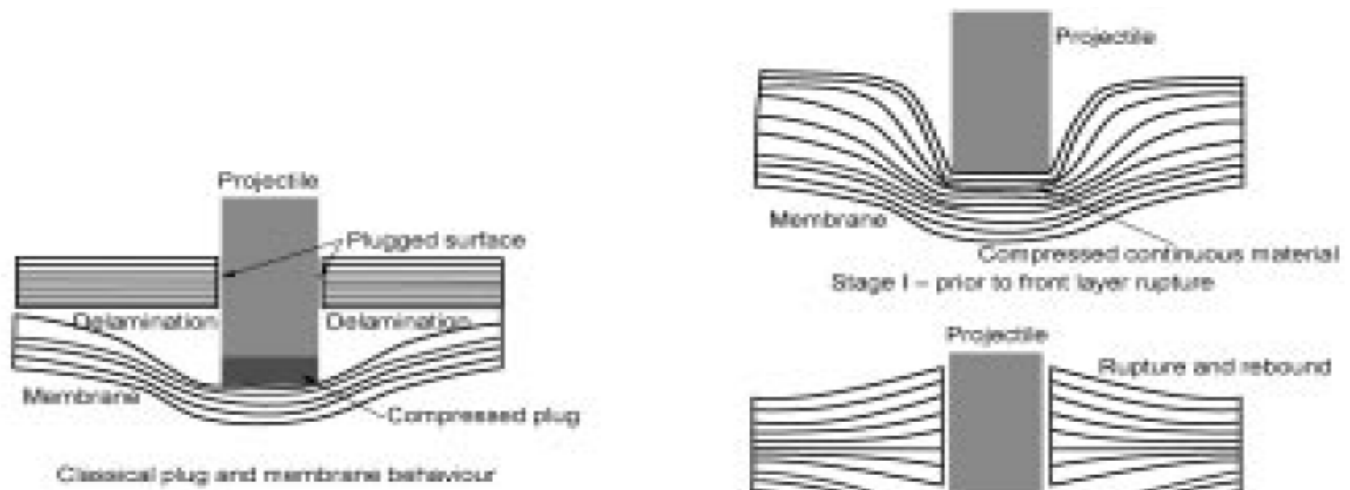

Stage I = prior to frone byer nughe

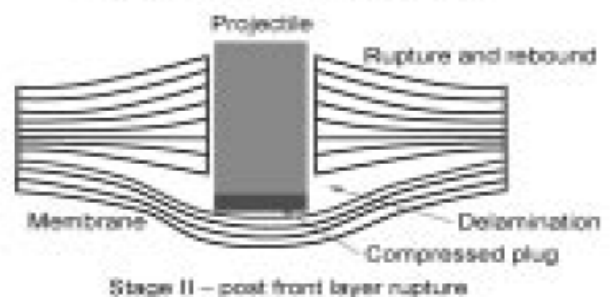

Fig. (15) Rigid and compliant behaviour during impact [8].

1- Synthesize a stiffer backing material to better support the ceramic - delaying the onset of ceramic tensile failure.

2- Synthesize a new ceramic which has improved tensile properties - delaying the onset of ceramic tensile failure. Paper Application of ceramics in armour production.

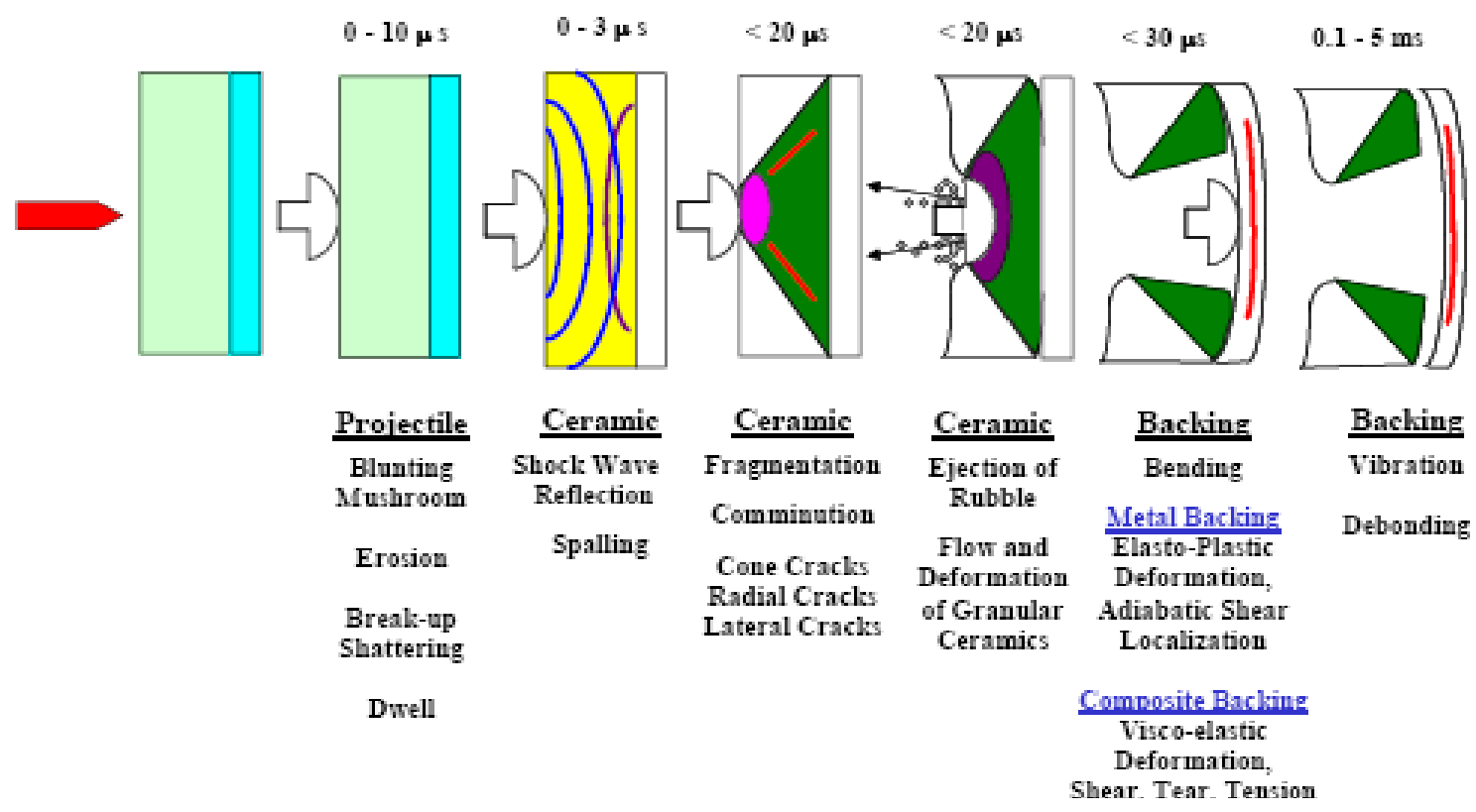

Fig. (16) damage evolutions in ceramic armours [33]

The ceramic tile was seen to load the projectile nose causing attrition and deceleration, at a rate governed by the yield strength of the projectile material. The ceramic fractured in the form of a conoid followed by tensile failure in the ceramic initiating at the ceramic/backing plate interface, opposite the impact location. Wilkins proposed that delaying the initiation of tensile failure would substantially increase the performance of ceramic composite armours by allowing more projectile erosion. 
There has been substantial interest recently in empirical studies of the failure of ceramic armour. $[4,6,33,48]$ present data for targets with a range of thin backing plate materials, and also for cases where no backing is used. The backing is shown to contribute substantially to the achievement of good ballistic performance in the ceramic. $[4,5,26,33]$ have used effectively semi-infinite backings and measured residual penetration depths into these as a guide to ceramic performance. They conclude that ballistic performance increases with increase in effective compressive strength of the ceramic. Using small calibre armour piercing projectiles, demonstrated that a negligible proportion of the projectile's kinetic energy $(\sim 0.2 \%)$ went into fracture of the ceramic.

The major energy dissipating mechanisms were identified as plastic deformation of both the backing plate $(20-40 \%)$ and the penetrator (10-15\%), and kinetic energy picked up by the ceramic debris (45-70\%). The backing plates for ceramic targets were not defeated by perforation, but rather bulged and necked to failure by ductile fracture. In the case of glass tiles the projectile core was not deformed by the glass and defeated the backing plate by perforation. These results suggest that a major aspect of the interaction is the transfer of momentum from the impacting projectile to a larger volume of ceramic which is ejected at high velocity. High speed cine and flash radiography confirm that momentum is conserved by the impulse delivered to the target producing a small forward velocity of the centre of mass of the impacted target. The high ejection velocity of fragmented glass debris, similar to the rate of projectile penetration, in the photographs of impacted glass by $[10,29]$ confirms the important part played by the transfer of momentum. While cone cracking has been studied extensively [11-36] in semi-infinite glass media, it has been studied less extensively in finite thickness bodies [16]. The ideal cone angle depends on the elastic properties of both indenter and brittle material [12], but for quasi-static ball indentations is generally around $68^{\circ}$ to the axis of indentation. Under controlled dynamic conditions the crack travels through a time varying stress field and hence significant, but predictable, departures from the ideal angle are observed $[12,40]$.

Ballistic impact tends to be an overload situation with little control and therefore it is extremely difficult to study the sequence of cracking. Nevertheless the cone shaped zone of damage simulated by [3] is similar to observed fracture conoids and at similar angles to cone cracks seen in quasi-static indentation of glass plates. $[8,10,17,37]$ have used high speed photography to study crack propagation in the ballistic impact of glass plates. They observe not only the propagation of cracks from the impact site but also the nucleation and growth of cracks in the stress field ahead of the damage front.

Studies of impact and shock loaded ceramics $[20,38]$ show that the Hugoniot elastic limit does not correlate in a simple manner with indications of microplastic yielding, and the fracture behaviour of ceramics is not simply interpreted in terms of the stress state. There is no clear correlation between the degree of ceramic fragmentation and ballistic resistance [21,42], with extremely tough ceramics such as the toughened zirconias showing no better ballistic performance than alumina ceramics.

This would be expected given that less than $1 \%$ of the projectile impact kinetic energy appears as fracture energy [8,39]. The degree of break-up in ballistic tests does however correlate well with ceramic toughness $[8,9,40]$. Tests on ceramics with a thick backing have shown that ballistic resistance is related to strength, although the appropriate strength parameter does not appear to be simply the Hugoniot elastic limit 
or the ceramic compressive strength $[5,36]$. It is noted that ceramic powders confined by a hydrostatic pressure can exhibit a significant effective flow stress [33], and confined ceramic powders themselves can provide substantial resistance to ballistic impact [42].

\section{MODELING OF COMPOSITE TARGET PENETRATION}

Modelling impact and penetration problems have been the subject of much interest especially for their application to defence and space technology. Due to the constant improvements of weapon technology, predicting the ballistic resistance and behaviour of armour under impact by a projectile is the subject of much experimental, analytical and numerical research. Nevertheless, the problem has not yet been fully understood or solved. Ballistic experiments are crucial to further understand the complexity of penetration mechanics in order to identify key parameters defining the perforation and damage phenomenon of the armour materials. The complexity of ballistic problems caused by the high number of intervening parameters like relative velocity, shape of colliding objects, relative stiffness and masses, location of contact, dimensions and boundary conditions, material characteristics, etc., increases when composite materials are involved, due to the orthotropic properties and distinct failure modes that may occur. Designing composite material ballistic armour thus requires a very large number of experimental tests, which are time and resources consuming. [20] presents threedimensional finite element models that investigate the performance of ceramiccomposite armours when subjected to normal and oblique impacts by 7.62 AP rounds. The finite element results are compared with experimental data from different sources both for normal and oblique impact, respectively. Simulation of the penetration processes as well as the evaluation of energy and stresses distributions within the impact zones highlight the difference between normal and oblique ballistic impact phenomena. The findings show that the distributions of global kinetic, internal and total energy versus time are similar for normal and oblique impact. However, the interlaminar stresses at the ceramic-composite interface and the forces at the projectile-ceramic interface for oblique impact are found to be smaller than those for normal impact. Finally, it is observed that the projectile erosion in oblique impact is slightly greater than that in normal impact. A typical finite element model of ceramiccomposite amour system consists of the normal and oblique impact of 60 conicalcylindrical steel projectiles on to ceramic-composite target. The steel projectile is 7.62 $\mathrm{mm}$ in diameter and $28.1 \mathrm{~mm}$ in length. Its performance is similar to that of a $7.62 \mathrm{~mm}$ NATO armour-piercing (AP) round. The target is AD96 alumina tile of $6.35 \mathrm{~mm}$ thickness supported by a high strength carbon/epoxy composite of $3.75 \mathrm{~mm}$ thickness. The thickness ratio is decided based on work by Hetherington [21] where it was concluded that the optimum thickness ratio of two component composite armour was: $\mathrm{h} 1=\mathrm{h} 2$ _ $4 \mathrm{~d} 2=\mathrm{d} 1$, where $\mathrm{h} 1$ is ceramic plate thickness $(\mathrm{mm}), \mathrm{h} 2$ is backing plate thickness $(\mathrm{mm}), \mathrm{d} 1$ is the density of ceramic, and $\mathrm{d} 2$ is density of backing plate. In this study, d1 $1 / 43720 \mathrm{~kg} / \mathrm{m} 3, \mathrm{~d} 21 / 41600 \mathrm{~kg} / \mathrm{m} 3$ and therefore $\mathrm{h} 1$ and $\mathrm{h} 2$ are designed as 6.35 and $3.75 \mathrm{~mm}$, respectively.

Two components, namely a ceramic plate and a composite plate, are used in the armour system. Figure (17) shows Finite element model and coordinates for normal impact. 


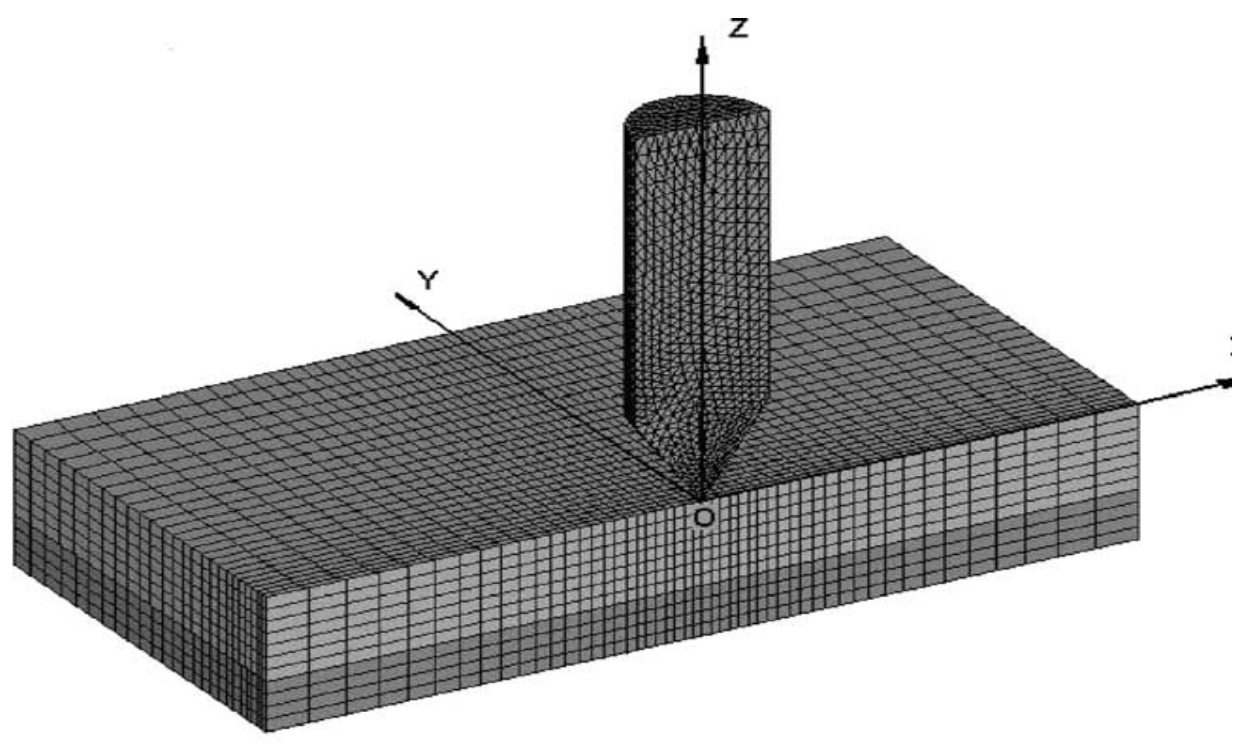

Fig. (17) Finite element model and coordinates for normal impact [20].

Simulations of normal and $30^{\circ}$ oblique impacts were performed, and some computation results are presented and discussed in this section. Initial velocities for both normal and oblique impact are $315 \mathrm{~m} / \mathrm{s}$. Solutions are terminated after 140 microsecond. Figures (18-21) show the results of modelling.

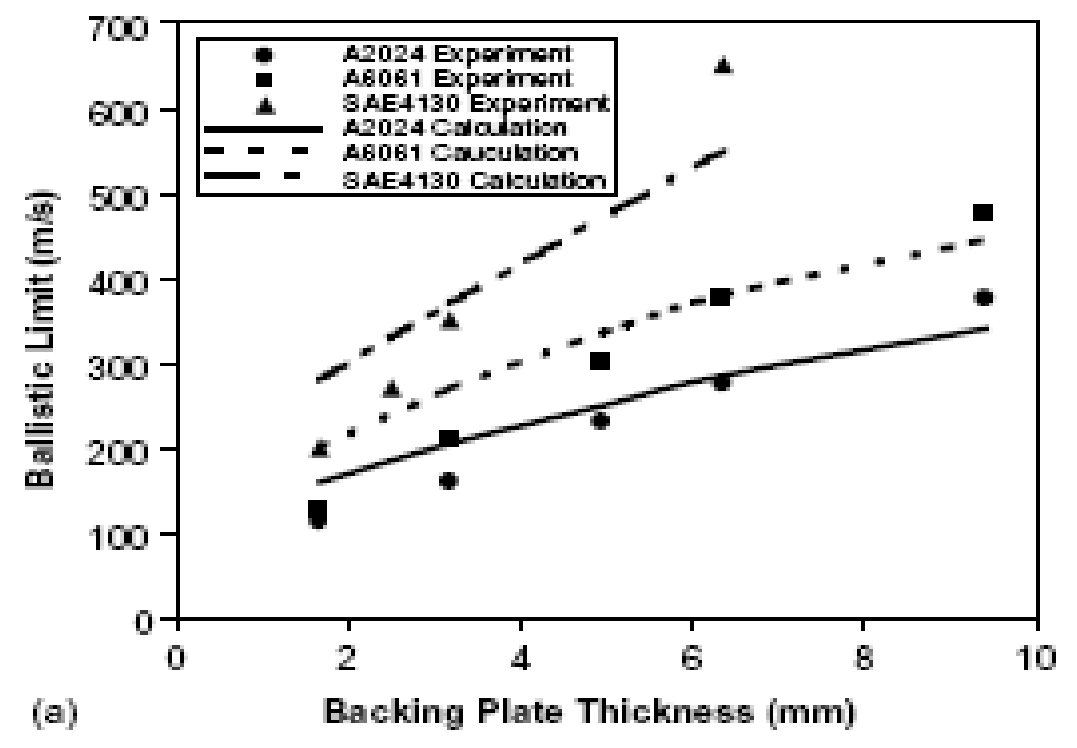

Fig. (18). Comparison between the experimental results for ballistic limit and projectile erosion and the results of the numerical model presented

(a) Ballistic limit [20] 


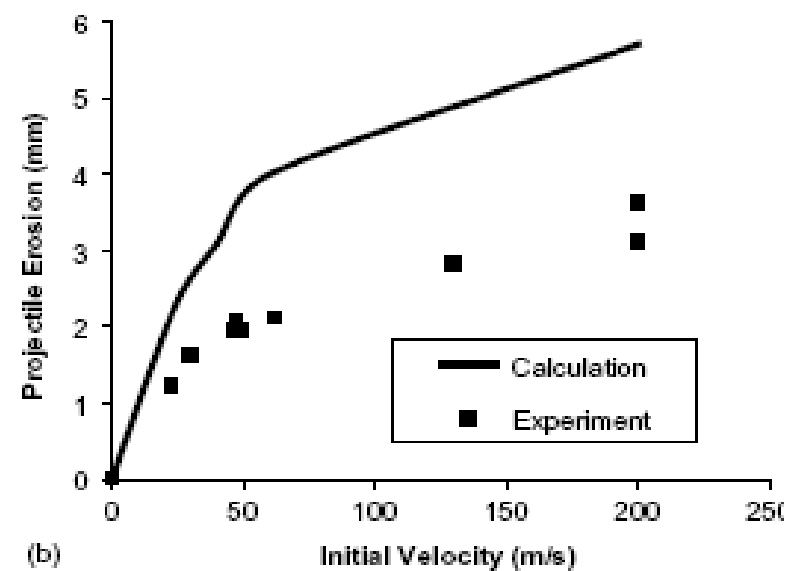

Fig. (19) Comparison between the experimental results for ballistic limit and projectile erosion and the results of the numerical model presented herein (b) projectile erosion [20].

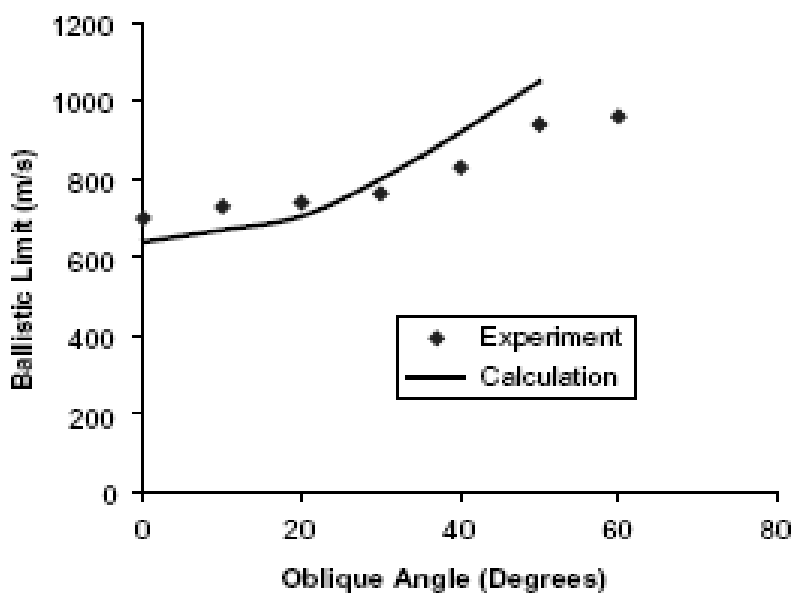

Fig. (20) Comparison of the ballistic limit computation with the experimental data for oblique impact[20].

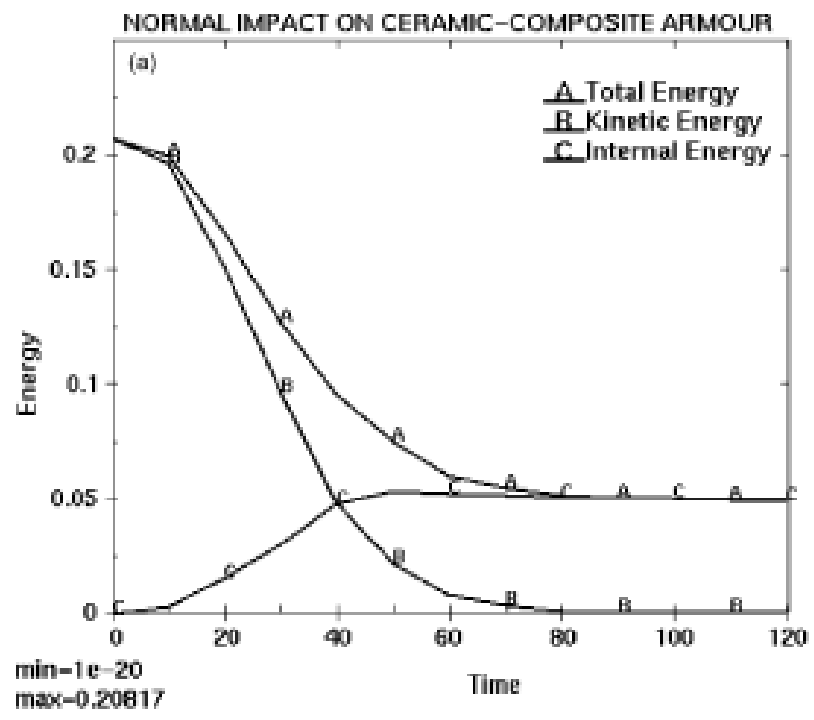

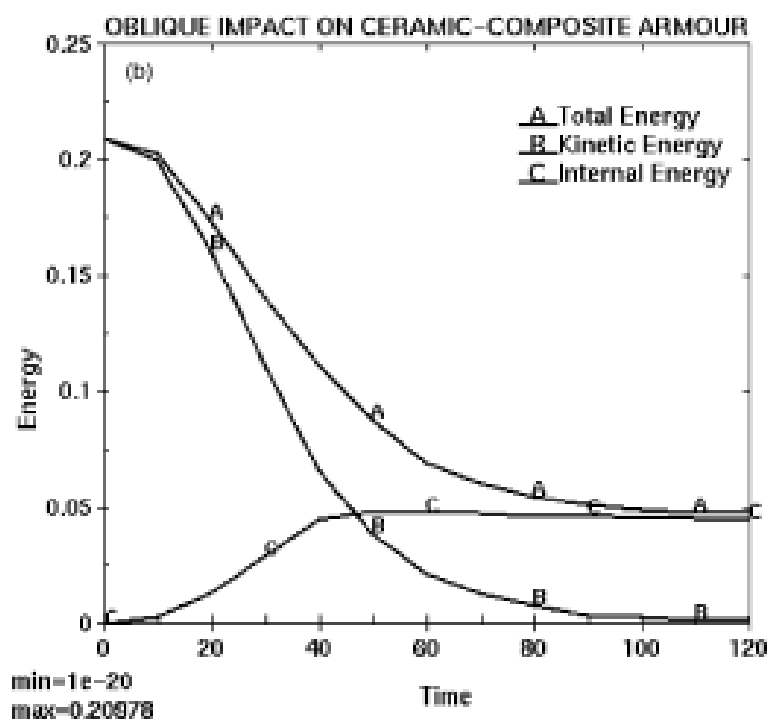

Fig. (21) Global energy (KJ) versus time (Is). (a) Normal impact and (b) oblique impact [20].

Models of the normal and oblique impacts of 7.62 AP round onto ceramic-composite armours were developed. Developed models had the ability to capture projectile erosion, ceramic conoid formation, as well as the failure of the ceramic and composite plates. The preliminary computations demonstrated reasonable correlation with existing experimental data, which allow us to conclude that the numerical models can be used for an improved design of lightweight armours. 
The various numerical simulations presented the details of penetration processes, distributions of energy, stresses etc. of normal and oblique impact at a velocity of 315 $\mathrm{m} / \mathrm{s}$. In particular, it was found that the distributions of global kinetic, internal and total energy versus time are similar for normal and oblique impact. However, the interlaminar stresses at the ceramic-composite interface and the forces at the projectile-ceramic interface for oblique impact were found to be smaller than those for normal impact. Furthermore, it was found that when a projectile impacts obliquely on the armour, it changes its angle during the perforation, forming an elliptical cavity at the tip of projectile. Finally, it was observed that the projectile erosion in oblique impact is slightly greater than that in normal impact.

\section{CONCLUSIONS}

From the above literature, a combination of ceramic tiles in platelets shape and size which allow multi hit capability plus putting a composite material as a backing material will introduce a completive armour that can fulfil the current requirement against small arm ammunitions. A light weight ceramic armour providing complete ballistic protection against penetrations from projectiles of calibre 0.30 to $7.62 \mathrm{~mm}$. armour piercing projectile consisting of a hard frangible facing the principle ingredient of which is a refractory oxide selected from alumina with reinforcement, bonded to a reinforced plastic back such as laminated fibre glass. This composite has an area density of approximately $84 \mathrm{kPa}$ and provides approximately 1.7 times the ballistic protection as compared to standard steel armour of equal area density.

\section{REFERENCES}

[1] Tracy C, Slavin M, Viechnicki D. "Ceramic failure during ballistic impact.", Advances in Ceramics: Fractography of Glasses and Ceramics 1988;22:295-306.

[2] G. G. CORBETT, I S. R. REID and W. JOHNSON. "IMPACT LOADING OF PLATES AND SHELLS BY FREE-FLYING PROJECTILES”, Int. J. Impact Engno Vol. 18, No. 2, pp. 141-230, 1996

[3] Zouheir Fawaz, Kamran Behdinan, Yigui Xu. "Optimum design of two-component composite armours against high-speed impact", Composite Structures 73, 2006, 253-262

[4] Wilkins ML. "Mechanics of penetration and perforation" International Journal of Engineering Science, 1978;16:793-807.

[5] Soon-Kil Chung. "Fracture characterization of armour ceramics" American Ceramic Society Bulletin, 1990; 69 (3) :358-66.

[6] O'Donnell RG. An investigation of the fragmentation behaviour of impacted ceramics. Journal of Materials Science Letters 1991;10:685-8.

[7] Anderson Jr CE, Royal Timmons SA. Ballistic performance of confined 99.5\% Al2O3 ceramic tiles. International Journal of Impact Engineering 1997;19(8):703713.

[8] J. JANG, R. PARK Failure of ceramic/fibre-reinforced plastic composites under hypervelocity impact loading journal of materials science 32 (1997).

[9] James B. Direct evidence for ceramic comminution ahead of penetrator. 17th International symposium on ballistics, Midrand, South Africa; 1998. vol. 3, p. 9-16. 
[10] Shockey DE, Marchand AH, Skaggs SR, Cort GE, Burkett MW, Parker R. Failure phenomenology of confined ceramic targets and impacting rods. International Journal of Impact Engineering 1990;9(3):263-75.

[11] Curran DR, Seaman L, Cooper T, Shockey DA. Micromechanical model for comminution and granular flow of brittle material under high strain rate application to penetration of ceramic targets. International Journal of Impact Engineering 1993;13(1):53-83.

[12] Anderson Jr CE, Morris BL. The ballistic performance of confined Al2O3 ceramic tiles. International Journal of Impact Engineering 1992;12(2):167-87.

[13] Franzen RR, Orphal DL, Anderson Jr CE. The influence of experimental design on depth of penetration (DOP) test results and derived ballistic efficiencies. International Journal of Impact Engineering 1997;19(8):727-37.

[14] Rosenberg Z, Yeshurun Y, Tsaliah J. More on the thick backing technique for ceramic tile against AP projectiles. 12th International symposium on ballistics. San Antonio, Texas, USA: ADPA; 1990. p. 197-201.

[15] Rosenberg Z, Yeshurun $Y$. The relation between ballistic efficiency and compressive strength of ceramic tiles. International Journal of Impact Engineering 1988;7(3):357-62.

[16] Woodward RL, Baxter BJ. Ballistic evaluation of ceramics: influence of test conditions. International Journal of Impact Engineering 1994;15(2):119-24.

[17] Gooch WA, Burkins MS. Ballistic development of US high density tungsten carbide ceramics. Pac Rim IV international conference on advanced ceramics and glass, Hawaii 2001:53-61.

[18] Murat Vural, Zeki Erim, Konduk BA, Ucisik AH. Ballistic performance of alumina ceramic armors. Pac Rim IV international conference on advanced ceramics and glass, Hawaii 2001:103-10.

[19] Sherman D, Brandon DG. The ballistic failure mechanisms and sequence in semiinfinite supported alumina tiles. Journal of Materials Research 1997;12(5):133543.

[20] Z. Fawaz W. Zheng, K. Behdinan Numerical simulation of normal and oblique ballistic impact on ceramic composite armours Composite Structures 63 (2004) 387-395

[21] J.L. Rapanotti, A. DeMontigny, M. Palmarini and A. Cantin, "Developing Vehicle Survivabilityon a Virtual Battlefield", NATO Modelling and Simulation Group Symposium, November 2001.

[22] J.L. Rapanotti, A. Cantin, and R.G. Dickinson, "Preliminary Study of Defensive Aids Suite Technology", DRDC Valcartier Technical Report (to be published).

[23] R.G. Lee, T.K. Garland-Collins, D.E. Johnson, E. Archer, C. Sparkes, G.M. Moss and A.W.Mowat, "GuidedWeapons", Bassey's (UK) Ltd., Third Edition 1998.

[24] J.L. Rapanotti, M. Palmarini and M. Dumont, "New computer and communications environments for light armoured vehicles", SPIE AeroSense Conference, April 2002.

[25] J.B. Bedard, "FERRET: Acoustic Threat Detection for Light Armoured Vehicles", DRDC Valcartier Technical Report (to be published).

[26] Satapathy S, Bedford A, Bless S. Behaviour of a yawed projectile penetrating a thin plate. Int J Impact Eng 1998;21(7):597-608.

[27] Plantema FJ. Sandwich construction. New York: Wiley, 1966.

[28] Vemuri Madhu,, K. Ramanjaneyul, T. Balakrishna Bhat, N.K. Gupta. An experimental study of penetration resistance of ceramic armour subjected to projectile impact International Journal of Impact Engineering 32 (2005) 337-350 
[29] Engineered Materials Handbook. Vol. 1: Composites. Philadelphia: ASM International, 1987.

[30] Divinycell H-grade. Technical Manual. DIAB AB, 1995.

[31] Goldsmith W, Sackman JL. An experimental study of energy absorption in impact on sandwich plates. Int J Impact Eng 1992;12(2):241-62.Spaceflight and Microgravity, http://www.estec.esa.nl/spaceflight/index.htm

[32] NASA Marshall Space Flight Center: Aerospace Success Story: Marshall Convergent Coating Development, 1994

[33] light weight ceramic armors Advances in Science and Technology Vol. 45 (2006) pp. $1729-1738$

[34] Roylance D, Wang SS. Ballistic materials and penetration mechanics. New York: Elsevier Scienti"c, 1980.

[35] Leech CM. The modelling of net and cloth dynamics. J Franklin Inst 1979;307(6):361\}78.

[36] Leech C, Hearle JWS, Mansell J. A variational model for the arrest of projectiles by woven cloth and nets. J Text Inst 1979;70(11):469\}78.

[37] Vinson JR, Zukas JA. On the ballistic impact of textile body armour. J Appl Mech 1975;42:263\}8.

[38] Taylor Jr WJ, Vinson JR. Modeling ballistic impact into \#exible materials. AIAA J 1990;28(12):2098\}103.

[39] Hearle JWS, Leech CM, Adeyefa A, Cork CR. Ballistic impact resistance of multilayer textile fabrics. DAJA37-79-C-0532, University of Manchester Institute of Science and Technology, 1981.

[40] Parga-Landa B, HernaH ndez-Olivares F. An analytical model to predict impact behaviour of soft armours. Int J Impact Engng 1995;16(3):455\}66.

[41] Chocron-Benloulo IS, RodrmHguez J, SaHnchez-GaH Ivez V. A simple analytical model to simulate textile fabric ballistic impact behaviour. Text Res J 1997;67(7):520\}8.

[42] Cunni! PM. An analysis of the system e!ects in woven fabrics under ballistic impact. Text Res J 1992;62(9):495\}509.

[43] Hearle JWS, Sultan MAl. Research on a basic study of the high-speed penetration dynamics of textile materials. DA-ERO-124-74-G0059. Department of Textile Technology. University of Manchester Institute of Science and Technology, 1974.

[44] Allied Signal Corporation. NIJ II and NIJ III-A armour constructed using heterogeneous combinations of GoldFlext and SpectraFlext fabric layers.

[45] Brown JR, Chappel PJC, Egglestone GT, Gellert EP. "A gas-gun facility for material impact studies using low velocity, low mass projectiles", J Phys E 1989;22:771-4. 